\title{
Primary Care Physicians' Perspectives on the Ethical Impact of the Electronic Medical Record
}

\author{
Tania Moerenhout, MD, MPhil, Gary S. Fischer, MD, Marlies Saelaert, MPhil, \\ An De Sutter, MD, PhD, Veerle Provoost, PhD, and Ignaas Devisch, PhD
}

Objective: The aim of this study is to explore whether specific ethical questions arise with the use of a shared electronic health record (EHR) system, based on the daily experience of primary care physicians (PCPs).

Methods: In this qualitative research project, we conducted 14 in-depth semistructured interviews with PCPs in a tertiary hospital setting.

Results: We identified 4 themes: 1) PCPs describe the EHR as a medicine with side effects, for which they provide suggestions for improvements; 2) A shared record raises ethical questions related to autonomy and trust; 3) Although use of the EHR often disturbs rapport with the patient, it can also support the patient-doctor interaction when it becomes an active part of the conversation; 4) A shared EHR may cause health care providers (and their relatives) to avoid seeking help for sensitive issues.

Discussion: PCPs fear access to results could cause confusion and anxiety in patients, resulting in tensions between autonomy and beneficence. Improved efficiency and quality of care with a shared EHR relies on doctors trusting each other's input to avoid duplicate tests. However, this might compromise a fundamental skeptical attitude in practicing medicine, and we should be aware of a risk of increased confirmation and anchoring bias.

Conclusion: The EHR is considered to be a work in progress-EHR design could be improved by examining physicians' coping strategies and implementing their suggestions for improvement. Ethical questions related to autonomy, trust, and the status of records that belong to doctor-patients need to be considered in future research and EHR development. (J Am Board Fam Med 2020;33:106-117.)

Keywords: Electronic Health Records, Health Information Exchange, Medical Ethics, Medical Informatics, Physician-Patient Relations, Primary Care Physicians, Qualitative Research, Quality of Health Care, Tertiary Care Centers

Already in 1982, Mark Siegler described confidentiality as a "decrepit concept." $\mathrm{He}$ estimated that somewhere between 25 and 100 health professionals and administrative personnel legitimately accessed a patient's record during a standard hospital stay, noting that a conflict arises between our traditional understanding of medical confidentiality

This article was externally peer reviewed.

Submitted 28 April 2019; revised 20 August 2019; accepted 20 August 2019.

From the Research Group Philosophy of Medicine and Ethics, Ghent University, Ghent, Belgium (TM, MS, ID); Department of Philosophy and Moral Sciences, Ghent University, Ghent, Belgium (TM, VP); Division of General Internal Medicine, University of Pittsburgh, Pittsburgh, PA (GF); Department of Public Health and Primary Care, Ghent University, Ghent, Belgium (TM, MS, AD, ID); Bioethics Institute Ghent, Ghent University, Ghent, Belgium (VP). and our desire to provide better and more comprehensive care to the patient. ${ }^{1-2}$ The electronic health record (EHR) allows for much more information to be stored and accessed by a wider circle of both medical personnel and patients. At the same time, it has become a complex and multifunctional tool also serving other functionalities such as finan-

Funding: TM is supported by a Clinical $\mathrm{PhD}$ fellowship (Research Foundation Flanders-Fonds Wetenschappelijk Onderzoek: Grant Number 1700618N). MS is supported by a BOF grant (Ghent University: Grant Number BOF15/ GOA/011).

Conflict of interest: none declared.

Corresponding author: Tania Moerenhout, MD, MPhil, Department of Public Health and Primary Care and Department of Philosophy and Moral Sciences, Ghent University-Campus Heymans (UZ Ghent), Corneel Heymanslaan 10, Building 6K3; 9000 Ghent, Belgium (E-mail: Tania.Moerenhout@ugent.be). 
cial reimbursement, risk management and quality and safety improvement. ${ }^{3}$ Although the EHR has been in use for quite some time now, its effect on the quality of care remains unclear. ${ }^{4-9}$ Correspondingly, its impact on the patient-doctor relationship also remains a topic of research. ${ }^{10,11}$ Two issues often arise: time spent on the computer for documentation takes away time directly spent with the patient, and the EHR can have a negative impact on the quality of the interaction (or rapport) with the patient. ${ }^{12,13}$ However, patient satisfaction does not seem to be negatively influenced by EHR use. ${ }^{14}$ With this study, we search to understand which ethical questions remain relevant today within a shared electronic record, specifically related to the triadic relationship between patient, doctor and EHR. Although several studies focus on challenges of EHR use, far fewer actually consider the lived experience of the physician.

\section{Objective}

The central aim of this qualitative research is to understand how primary care physicians (PCPs) integrate the EHR into their workflow and whether specific ethical questions arise while sharing medical information both with other practitioners and with patients.

\section{Materials and Methods}

\section{Theoretical Framework}

This study adheres to a framework of technological mediation and postphenomenology. A postphenomenological approach to technology combines the empirical orientation of Science and Technology Studies with a more conceptual philosophical analysis. ${ }^{15}$ A technology is then perceived as something that mediates the way we experience the world. ${ }^{16}$ This also applies to the moral role of technologies: "by mediating human experiences and practices... technologies mediate moral decisions and actions." ${ }^{17}$ In the classic example of the gun debate, technological mediation does not assume that "guns kill people," nor that "people kill people," but the "gunman," a hybrid of human and nonhuman elements, kills people. ${ }^{17}$ The gunman becomes a new entity with specific moral options. In this sense a technology is neither a moral agent, nor a neutral instrument: it is a moral mediator. The central perspective is that of the technologically mediated subject. ${ }^{17}$ This theoretical framework in- formed the development of interview questions and served as a background for data analysis, adhering to an ethical-constructive technology assessment approach. $^{18}$

\section{Design}

Within a qualitative research protocol, semistructured interviews with PCPs were studied using thematic analysis. A thorough literature search informed the interview guide (see Appendix). Although the initial questionnaire contained questions referring to the moral concepts of autonomy and confidentiality, it also allowed for participants to address other themes. The interview guide was developed through intensive deliberation with all authors until consensus was reached. Responses from previous interviews were integrated in the follow-up questions presented to succeeding participants in an iterative process. The first author conducted all interviews. She is a Belgian primary care physician (PCP) with a Master's degree in Philosophy who has completed a course in qualitative research methods in Public Health, received additional training in interviews with experts, and gained experience interviewing doctors in a previous study. The research protocol was approved by the Institutional Review Board of the University of Pittsburgh (IRB Number PRO17010359).

\section{Participants}

Participants were recruited in an academic general internal medicine outpatient practice embedded in a tertiary hospital in Pittsburgh, PA, through a purposive, convenience-based sampling process. ${ }^{19}$ The practice includes 46 faculty physicians. Physicians use Epic software and patients can access certain portions of the EHR and message their doctors through a portal system. The second author facilitated recruiting physician participants. The first author presented the study at a regular meeting of PCPs, after which they were given the opportunity to sign up for an interview. The main characteristics of the sample are shown in Table 1. Fourteen physicians consented to an interview. All interviews took place between February and May 2017 and lasted between 30 and 74 minutes. Data saturation was reached after 11 interviews, but 14 interviews were completed to establish a dataset that is both rich and thick. ${ }^{20-21}$ 
Table 1. Characteristics of the Sample

\begin{tabular}{|c|c|c|c|c|}
\hline PCP & Gender & $\begin{array}{l}\text { Age Range } \\
\text { (Years) }\end{array}$ & $\begin{array}{l}\text { Years of Experience } \\
\text { in the US (Range) }\end{array}$ & $\begin{array}{l}\text { Hours of Patient Contact per Week } \\
\text { (Excluding Inpatient Care) }\end{array}$ \\
\hline 1 & M & 31 to 35 & 1 to 5 & 30 \\
\hline 2 & $\mathrm{~F}$ & 56 to 60 & 31 to 35 & 25 to 30 \\
\hline 3 & $\mathrm{~F}$ & 26 to 30 & 1 to 5 & 24 \\
\hline 4 & M & 61 to 65 & 31 to 35 & 20 \\
\hline 5 & M & 61 to 65 & 31 to 35 & 24 \\
\hline 6 & $\mathrm{~F}$ & 61 to 65 & 31 to 35 & 20 \\
\hline 7 & $\mathrm{~F}$ & 46 to 50 & 11 to 15 & 27 \\
\hline 8 & $\mathrm{~F}$ & 56 to 60 & 16 to 20 & 15 to 25 \\
\hline 9 & M & 41 to 45 & 11 to 15 & 12 \\
\hline 10 & $\mathrm{~F}$ & 41 to 45 & 11 to 15 & 4 \\
\hline 11 & $\mathrm{~F}$ & 51 to 55 & 21 to 25 & 20 \\
\hline 12 & M & 46 to 50 & 11 to 15 & 21 \\
\hline 13 & M & 31 to 35 & 5 to 10 & 7 \\
\hline 14 & $\mathrm{~F}$ & 46 to 50 & 16 to 20 & 12 \\
\hline
\end{tabular}

F, female; M, male; PCP, primary care physicians.

\section{Data Analysis}

All interviews were recorded digitally, transcribed verbatim and coded in NVivo 12 (QSR International, Burlington, MA) by the first author. Three interviews were also studied and coded by a second researcher (MS) and elaborately discussed until consensus was reached. The first author continued the coding process with the established code book, expanding with new codes when necessary. The procedure of including a second researcher (MS) extended throughout the data analysis process and combined peer debriefing with a systematic audit trail to assert trustworthiness and credibility of the data analysis. ${ }^{22}$ The final coding scheme consisted of both deductive (based on the literature search and interview questions) and inductive (emerging from the interviews) codes. The thematic analysis process adhered to the 6 phases described by Braun and Clarke. ${ }^{23}$ All coauthors provided input at different stages of this process. Moreover, both the Standards for Reporting Qualitative Research (SRQR) and Consolidated criteria for reporting qualitative research (COREQ) guidelines for reporting qualitative research were observed. ${ }^{24-25}$

\section{Results}

Three major themes and 1 minor theme were identified: 1) PCPs describe the EHR as a medicine with side effects, for which they provide suggestions for improvements; 2) a digitally shared record raises ethical questions related to autonomy and trust; 3) although use of the EHR often disturbs rapport with the patient, it can also support the patient-doctor interaction when it becomes an active part of the conversation; 4) minor theme: a shared record may cause care providers (and their relatives) to avoid seeking help for sensitive issues. A selection of quotes per theme is available in Table 2.

\section{A Medicine with Side Effects}

All participants paint a carefully nuanced picture of the electronic record. They acknowledge it as an effective tool with a positive impact on the quality of care. They highly value having medical information available "at their fingertips": in real time, searchable and easily accessible. They also deem the information to be more accurate. The record helps them in preventive care as well as chronic disease management with extra functionalities of checklists, reminders, and smart algorithms. Some doctors emphasize how the EHR facilitates patient population management and reaching quality targets. Not only does the EHR solve many practical issues occurring with paper records, it also informs the PCP about everything that happens to the patient outside of the consultation room:

"I've actually been here long enough to remember the paper chart days, and I remember the transition to the EHR. I can do a comparison and I know so much more about what happens not in my office now. I know what happened in the emergency department last week. I 
Table 2. A Selection of Quotes Per Theme

Theme Quotes

(1) PCPs describe the EHR as a medicine with side effects, for which they provide suggestions for improvements.

(2) A digitally shared record raises ethical questions related to autonomy and trust.
2. So I think it increases the accuracy, I think it increases your real-time interpretation of data. Because you're doing it right then and there. You're not saying: I'll check it later, and then you forget, or, you know. So... I think it helps tremendously.

10. So, you know I think, ehm, it's an incredible tool with many flaws that make things hard, ehm, eh to sort of fully utilize it. Ehm, you know, I think the things that are ... [exhales] most helpful for me. Ehm, so one is the ability to see other people's notes and to sort of easily sort through things.

12. Ehm, but I do think as a profession, we need to figure out ways to spend less time on the computer. Ehm and that's why I like these ideas of, you know, group message or group notes, whether dictation does some of it, or, you know, however we evolve to that, I think we have to, as a profession, figure out ways to spend the same amount of time with the patients, or slightly more time with the patients, but be doing eh, somebody else doing more of the documentation, or the computer doing the documentation, or pulling from somewhere and then this kind of decision support stuff, maybe being done by nonphysicians.

13. I think it could become a really powerful tool, but I just don't think we're there yet.

Autonomy vs. Paternalism

2. I think that's a mixed bag. Eh, what if you don't like the diagnosis of obesity? What if you don't like the diagnosis of anxiety? But they happen to be real diagnoses. Ehm, so I think that ehm ... I don't know, I think it's better the way it is now, where you bring me the changes and maybe you and I need to have a talk about what obesity means, you know. So...

3. Which can happen, which does happen I would say a lot, like, people see their labs before I've replied to them and then they get very nervous about some, like, very stupid lab abnormality that is like, completely irrelevant, and then they're, you know, they're emailing me or calling me like: oh my gosh, I saw this, what does this mean, and they're freaking out. So, that's the only I think downside.

9. Ah ... I think there's advantages and disadvantages to that and I think the devil's in the details. Ehm ... there are times that a $\mathrm{p}_{-}$, I can envision a time where patients would ask that something was changed or added, that actually, probably, is: oh, that's really helpful, you know. "Oh, I actually had ehm, this surgery on my knee in 1998 and it's not in my chart", fine, that's easy, right? [ . . . If somebody says: "take out all references to me using opioids" ... I don't think that we should oblige that request if it's medically appropriately there. Ehm, so, I think if we develop a system where they could do a request to

change ... I think that's fine. Ehm, having them go in and just edit things without anybody knowing about their edits, sounds a little bit suspect.

$\underline{\text { Trust }}$

1. I mean, it's hard to completely trust another provider to, you know. [ . . . I look up patients beforehand, and it's the same thing when I admit them as inpatients. I, I'll go through their records and, some of it is objective data that I know is true, you know, if someone got certain labs that I know, then, that, those are reliable, but at the same time I'm also looking at other people's documentations, eh, or people's documentation and their notes, and then I'm really trusting the history that they got and people don't always get a history that I would think is acceptable. So, I think it, it introduces all sorts of bias, so... You know, and I've seen that happen especially when I was a resident, ehm, you know if you were busy, you would get a page from the emergency department saying that you were gonna get a patient. And, even before, even before someone called to tell you about them, you could go onto their chart and I would go onto the chart and read everything and look at like, the labs and imaging, and the history that I could, you know, whatever they had sorted writing, and sometimes based on that I would think of a diagnosis and then talk to the patient and realize it's actually a completely different story. Ehm, so I, I would be very, very hesitant to only treat someone based on the chart.

6. I had an interesting patient, brand new to me, last week, who was very suspicious of the electronic health record. And felt like: anybody can read it. Ehm, sometimes when I encounter that, eh, I do tell them that people lose their jobs for reading-and I've seen it happen-for reading a chart that they're, shouldn't have privy to. They get caught and they get fired. But, truth be told, I bet you not everybody is caught and fired. Ehm, so I kind of understand that.

7. I go through the medication list AGAIN, because some of my medical assistants don't go through them the way they should. And sometimes I use it anyway to go through, because even if the patient says they went through it, I can't remember what they're taking. 


Theme Quotes

(3) Although use of the EHR often disturbs rapport with the patient, it can also support the patient-doctor interaction when it becomes an active part of the conversation.
(4) Minor theme: A shared record may cause care providers (and their relatives) to avoid seeking help for sensitive issues.

\section{Disturbs Rapport}

6. Oftentimes when I have that paper, in, in my physical interaction with the patient, I can be standing right next to the patient and looking at this paper together. And that never happens with the computer, there is always this distance between me and the patient when I'm working with the computer.

7. So some of my patients, are here for a lot of, psychosocial issues, and usually that does not lend itself well to typing on the computer. You need to be looking at them and talking to them and I scribble notes on paper and I actually do my notes later, that takes longer.

13. But then I feel like maybe, you know, I'm not making the eye contact with the patient that I want to. Ehm, even though I still try to be very conscientious to try and make as much eye contact as I can, I'm trying to, balancing kind of the, the burden of documentation, everything I have to do with the EHR in the course of the visit, with still trying to provide like the most personal care I can. So I think that they EHR does take away from that, you know, the ideal connection that you can make with a patient.

\section{Coping Strategies}

1. So sometimes when, you know, they come in and if I want to review their lab results then I'll actually point the screen towards them and show them all the results.

5. At that moment when I turn to the computer-that is actually when I start to engage the patient. Because I open up the screen to them and we have 22 inch monitors in every one of the rooms. And I show them often their latest labs, perhaps some diagnostic studies that were recently done, ehm, and then I begin to talk to them about what I would like to do at this point. I'm talking to them and at the same time I'm entering the orders, eh, and explaining to them why I am doing that.

5. Eh, depending on the patient. Some people, so ... for my physician professors, ehm, those people I've had a longstanding rapport of and I'll release it to them. [ ... . But there is still some judgment done, eh, I mean, so there are things that I will not put in a note assuming I have a longstanding relationship with the patient that I may be misconstrued by others, or really because we, I sit in the middle of this academic center and physicians have access, have full unfettered access to charts, I may withhold from the record.

6. Eh, a lot of my patients are faculty here. So this, so I'm, I'm very cautious about that. Eh, and I will have a larger definition of what's sensitive for our faculty. [...] So, ehm, I do offer, if there is some material that they don't wanna have included in the EHR, I am willing to keep shadow charts. But we talk about the pros and cons of that [...] This is also, you know, someone who is a spouse of a faculty member, prominent faculty member.

8. Like recently I had a health care provider, and she was very offended when my nurse asked her in the pre-test about a certain medication that showed up on her med list, and she said: "oh no, I don't take it, I don't take it". So the MA [medical assistant] came to me before I went in, like I said, she warned me and she said: "I was doing med reconciliation, and patient said that she's not on this medication, but it showed that she just picked up a refill". [...] And then I finished everything and towards the end, coming up, and I said: "Eh, just so that you're aware that it's in your chart, which is the reason we're asking that, I wanna make sure so that I can take it out of your chart". She said: "I don't want this information in my chart".

EHR, electronic health record; PCPs, primary care physicians.

know what the consultant told them. I would not have known these things. The patient could not really tell me these things a lot of the time, so I was in the dark a lot, and I feel like that is not the case anymore." (PCP 7)

However, many "side effects" were also mentioned during the interviews. First, 9 physicians describe how the EHR interrupts the conversation with the patient and disturbs rapport. Second, half of the participants experience alert fatigue due to the many pop-ups that are not always useful to them. Third, the EHR is described as "bulky" or "clunky," because of the phenomena of overdocumentation and copy-paste notes. Navigating all the available information requires a lot of clicking, leading to the experience of the EHR not being user-friendly. Fourth, PCPs generally think the EHR is time-consuming because it requires a lot of extra work. Some interviewees specify that this extra work is a consequence of the modern requirements of practicing medicine: teamwork, prevention and chronic disease management all intensify the need for registration. And fifth, the record is experienced by half of the interviewees as rigid, both in how difficult it is to change certain information, and in one-size-fits-all alerts that are not adapted to individual patient characteristics. 
Overall, the record is described as a work in progress. All but 1 physician also provide suggestions for improving the above mentioned side effects, such as the addition of cross-referencing, risk calculators and scheduling, and an upgrade of search methods, messaging, automation and overall user-friendliness. Moreover, many physicians have developed coping strategies to integrate the computer into the conversation with the patient. This is further explored in the third theme. Two doctors emphasize the importance of including physicians into the design process of EHR development.

\section{Ethical Questions}

With (certain parts of) EHRs being accessible to patients, long-existing ethical questions mainly involving autonomy and trust are being reformulated within the digital patient-doctor relationship.

\section{Conflict between Respect for Autonomy and Beneficence}

Twelve interviewees describe situations in their daily workflow related to the EHR where they experience a conflict between the principles of respect for autonomy and beneficence. When medical results are shared electronically, doctors worry that patients may find it difficult to interpret these results correctly, potentially causing confusion and anxiety. Some PCPs suggest providing an explanation with the results. Others argue it would be better to select which information becomes accessible, although they acknowledge this could result in a paternalistic attitude:

"I think-and I do not mean this in a patronizing way-I think patients would be better served if we could pick and choose information that we give them. Now I know that could be abusive, you could delete or not send them things. But... I still think that they do not need every single solitary thing in the chemistry panel that has no relevance to them." (PCP 2)

The majority of interviewees are not comfortable with patients adding or changing information, unless under strict conditions (such as source identification, separate sections, or limited to certain types of information, for example from self-tracking activities).

There is no clear uniformity in the answers to the question what purpose patient access should serve. Some mention patient education and engagement, while others highlight a better compliance as a preferred outcome.
One PCP described a case that fleshes out the ethical conflict between respect for autonomy and beneficence at the level of a shared EHR. He talked about his strategy to include the background story of a patient to his notes, a patient who was oftentimes written off by medical practitioners as "difficult." However, when he came to understand her background of rape, prostitution, and homelessness, he could see her in a different light. By documenting this in the EHR and making it accessible to colleagues, he hoped they too could see her in a more compassionate way. When asked whether he had discussed this approach with the patient, he responded:

"That is a good question, I've never asked her specifically if she knows that it is in there... That is a really interesting ethical question. I've never thought about it, because my goal in documenting it was to decrease the judgment that she would get. And I think that it probably will if someone reads it. But... I never thought to ask her if that is something that she would want redacted... I think there would be a lot of emotions involved that would have to be overcome for her to appreciate the benefits of the documentation." (PCP 9)

This clearly shows how some doctors struggle between respect for autonomy-by consulting their patients' preferences and providing them with a comprehensible explanation-and beneficence, where they act in the best interest of the patient but risk a certain level of paternalism.

\section{Trust Versus Skepticism}

EHR use impacts trust both in the patient-doctor relationship and in doctor-doctor interactions. Regarding the patient-doctor relationship, some PCPs note that a minority of patients do not trust EHRs (or the way they are used and shared) because so many care providers and other personnel can access their information. Some physicians use the information that colleagues made available as a way to double-check what patients tell them:

"It is also belpful when patients try to hoodwink you by saying: "oh, that doctor said you should give the prescription"-they give you information based on what their needs are. And you recognize that is not the same as what was documented by the other physician." (PCP 8)

Contrarily, another participant thinks patient access to the record may actually increase trust and compliance in patients. 
When it comes to doctor-doctor interactions, 3 participants describe how they are skeptical of information in the record added by colleagues:

"I always say: take it with a grain of salt. That bistory is only as good as what the person before you heard - the history has nothing to do with what was said." (PCP 14)

PCP 1 also mentioned how he could be put on the wrong track when reading a patient's record before seeing them: often the face-to-face contact would lead him to a very different conclusion than the one he had in mind solely based on the information in the record. In this sense, the diagnostic process requires a certain level of skepticism.

\section{EHRs' Disturbing and Supporting Impact on the Patient-Doctor Interaction}

"I enter the room, introduce myself to [the patient] and do not touch the computer. It has been a personal decision I made a long time ago, that on engaging with the patient not to focus on the computer. First the patient. Second, it has to do with establishing rapport with the patient." (PCP 5)

As mentioned in the first theme, a majority of participants feel the EHR disturbs rapport within the patient-doctor conversation, mostly by interfering with eye contact and breaking the flow of the narrative. Twelve physicians comment on the design or configuration of the examination room and how this may hinder (or facilitate) computer integration into the conversation.

To avoid a negative impact, PCPs describe a diverse set of coping strategies: studying the record before the encounter ("chart prepping"), avoiding the computer during (part of) the conversation, giving patients an explanation for what they are doing while interacting with the computer, or jotting down notes on paper instead of using the EHR.

On the other hand, the EHR can also be a tool that supports the conversation. Despite the hindrance computers cause, most physicians provide examples where they share the screen with patients: to discuss results, to look at health maintenance overviews or to reconcile medication lists. This active engagement of the computer into the conversation with the patient seems to counterbalance the negative effects of computer use. About half of the participants provide examples of beneficial computer practices, such as using information in the EHR as a conversation starter, or as a tool for patient education.

"The EHR can summarize a lot of data and serve as the starting point for a very constructive conversation between the patient and the physician that I think can actually cultivate trust in the relationship." (PCP 13)

\section{Sensitive Information: Care Provider as Patient}

When talking about handling sensitive information in a shared record, 6 physicians spontaneously mentioned examples of care providers or their close family members seeking medical help.

"A good example is: one of my patients was battered by her husband who is a faculty member here. That would be very sensitive. So, those would be... what I consider to be sensitive." (РCP 6)

"I think some patients are very concerned about some of their information [being] available, especially if they are health care providers themselves." (PCP 8)

These participants were especially careful about handling sensitive information of physicians working at the same center. The awareness of "unfettered access to charts" (PCP 5) by physicians withheld some of sharing sensitive information in the record. Two participants also mentioned examples related to family members of faculty requesting information being removed from their records, one related to sexual orientation and another to antidepressant medication. Another interviewee was worried about physicians getting individual insurance in their next job, if certain information-such as use of antidepressants- became accessible to third parties.

\section{Discussion}

The interviewed physicians describe the EHR as a "medicine with side effects." We see a similar analysis of benefits and concerns in previous research. ${ }^{26}$ First and foremost, participants view EHR use as beneficial to quality of care. This is in line with other studies that focus on physicians with EHR experience, ${ }^{27,28}$ although another interview study found the opposite. ${ }^{29}$ Two doctors rightfully note that a more intensive collaboration between users (both physicians and patients) and EHR developers could prove beneficial in creating a more efficient digital record and avoiding problems.

\section{Autonomy Versus Paternalism}

Our participants are struggling to find a balance between beneficence and respect for autonomy. ${ }^{30}$ 
Previous research has shown that care providers are skeptical of giving patients granular control over their EHR information, fearing it could damage the patient-doctor relationship and negatively impact quality of care. ${ }^{31}$ Patients, on the other hand, value individual control and privacy. ${ }^{32}$ Moreover, some physicians consider a better patient compliance to be the most important outcome measure for patient portal systems. Patient empowerment and compliance do not always coincide and EHR design will probably vary depending on which goal is prioritized. Although patient portals have been active for some time now, it is not clear whether patients also understand the information in the EHR—although this is a vital prerequisite for autonomy and informed consent. ${ }^{33}$ Doctors in other studies express similar concerns about potentially harming patients by creating confusion or anxiety, especially when interpreting lab results. ${ }^{26,34}$

We argue that these findings urge us to rethink which goal a shared EHR should serve: patient empowerment? Compliance? Or something else? Second, we should consider how patient portals can benefit patients in a meaningful way, through userfriendliness, comprehensible information presentation, and support for vulnerable patients.

\section{Trust within Doctor-Doctor Interactions}

EHR integration aims to improve quality of care by decreasing redundancy and by avoiding unnecessarily repeated tests. ${ }^{6,26,35}$ To reach this goal, trust between care providers is essential. Many aspects of EHR design aim at exchanging information that needs to be trusted by the next care provider. This study shows that skepticism, understood as an attitude aimed at reducing anchoring and confirmation bias, could be an underestimated aspect of the diagnostic process. A certain level of skepticism remains an important diagnostic tool that may not get the attention it deserves in terms of digitalization of the record. In medicine, a vital part of the job is to identify omissions, which sometimes requires "starting all over again." One may wonder whether the current EHR design risks increasing anchoring and confirmation bias. Interestingly, the solution may also be digital in the form of decision aids. A deliberate reflection protocol and diagnostic checklists have shown small but consistent benefits in reducing errors. ${ }^{36}$

\section{Active Integration of the EHR into the Patient- Doctor Conversation}

When a physician is fully absorbed by the computer screen and loses focus on the patient, the EHR may undermine rapport. On the other hand, an active use of the computer in the conversation which also engages the patient, can prove beneficial. This is in line with previous research results: active information sharing allows for more patient engagement with the EHR, reducing the negative impact of the computer on the patient-doctor interaction and improving collaboration. ${ }^{37}$ Several strategies such as using the computer to facilitate conversation, adjusting room design and maintaining eye contact while typing are evidence-based recommended practices, which are also acknowledged here. ${ }^{11,38}$ Despite concerns some PCP expressed, sharing notes with patients does not seem to negatively affect the patient-doctor relationship. $^{39}$

\section{Effect of the EHR on Care Providers' Help-Seeking Bebavior}

Several participants highlight difficulties in treating sensitive issues presented by doctor-patients, especially when it concerns faculty working at the same hospital or their family members. An increasing body of literature shows that physicians often resort to self-treatment and experience multiple barriers in help-seeking behavior. ${ }^{40-42}$ This study reveals that digitally sharing information might actually be another, rather unexpected, barrier in help-seeking behavior of medical care providers, one that intersects with previously examined barriers such as a feeling of embarrassment, cultural issues, and confidentiality questions. ${ }^{42}$ Should physicians' records be given a more stringent confidentiality status? More research is needed to understand how information sharing through EHRs affects help-seeking behavior of medical personnel.

\section{Conclusion}

This study, based on the daily experience of PCPs working with their EHR system, identified ethical questions related to patient autonomy, trust, and help-seeking behavior of doctor-patients within the triadic relationship of patient, doctor and shared EHR. These findings could inform both EHR design and future research, and is one of the first steps 
into creating an ethical framework for a shared EHR.

The authors thank all participating primary care physicians for the time and effort they put into this interview study. We also thank 3 anonymous reviewers for their useful comments and suggestions.

To see this article online, please go to: http://jabfm.org/content/ 33/1/106.full.

\section{References}

1. Siegler M. Confidentiality in medicine-A decrepit concept. N Engl J Med 1982;307:1518-21.

2. Anesi GL. The "decrepit concept" of confidentiality, 30 years later. Virtual Mentor 2012;14:708-11.

3. de Ruiter HP, Liaschenko J, Angus J. Problems with the electronic health record. Nurs Philos 2016;17: 49-58.

4. Campanella P, Lovato E, Marone C, et al. The impact of electronic health records on healthcare quality: a systematic review and meta-analysis. Eur J Public Health 2016;26:60-4.

5. Moja L, Kwag KH, Lytras T, et al. Effectiveness of computerized decision support systems linked to electronic health records: a systematic review and meta-analysis. Am J Public Health 2014;104:e12e22.

6. Hersh WR, Totten AM, Eden KB, et al. Outcomes from health information exchange: systematic review and future research needs. JMIR Med Inform 2015; $3: \mathrm{e} 39$.

7. Nguyen L, Bellucci E, Nguyen LT. Electronic health records implementation: an evaluation of information system impact and contingency factors. Int J Med Inform 2014;83:779-96.

8. Rahurkar S, Vest JR, Menachemi N. Despite the spread of health information exchange, there is little evidence of its impact on cost, use, and quality of care. Health Aff 2015;34:477-83.

9. Lau F, Price M, Boyd J, et al. Impact of electronic medical record on physician practice in office settings: a systematic review. BMC Med Inform Decis Mak 2012;12:10.

10. Crampton NH, Reis S, Shachak A. Computers in the clinical encounter: a scoping review and thematic analysis. J Am Med Inform Assoc 2016;23:654-65.

11. Street RL Jr, Liu L, Farber NJ, et al. Provider interaction with the electronic health record: the effects on patient-centered communication in medical encounters. Patient Educ Couns 2014;96: 315-9.

12. Pelland KD, Baier RR, Gardner RL. 'It is like texting at the dinner table': a qualitative analysis of the impact of electronic health records on patient-physician interaction in hospitals. J Innov Health Inform 2017;24:216-23.
13. Hill RG Jr, Sears LM, Melanson SW. 4000 clicks: a productivity analysis of electronic medical records in a community hospital ED. Am J Emerg Med 2013; 31:1591-4.

14. Alkureishi MA, Lee WW, Lyons M, et al. Impact of electronic medical record use on the patient-doctor relationship and communication: a systematic review. J Gen Intern Med 2016;31:548-60.

15. Rosenberger R, Verbeek PP, eds. Postphenomenological investigations. Essays on human-technology relations. Washington, DC: Rowman \& Littlefield: Lexington Books; 2015; 9-19.

16. Ihde D. Postphenomenology and technoscience: the Peking University lectures. New York, NY: SUNY Press; 2009, 34.

17. Verbeek PP. Moralizing technology. Understanding and designing the morality of things. Chicago, IL: University of Chicago Press; 2011; 41-65.

18. Kiran AH, Oudshoorn N, Verbeek PP. Beyond checklists: toward an ethical-constructive technology assessment, J Responsible Innov 2015;2:5-19.

19. Silverman D. Doing qualitative research. London, UK: SAGE Publications; 2013; 141-58.

20. Fusch PI, Ness LR. Are we there yet? Data saturation in qualitative research. Qual Report 2015;20: 1408-16.

21. Mason M. Sample size and saturation in $\mathrm{PhD}$ studies using qualitative interviews. Available from: http:// www.qualitative-research.net/index.php/fqs/article/ view/1428/3027. Accessed December 29, 2018.

22. Creswell JW, Miller DL. Determining validity in qualitative inquiry. Theory into practice 2000;39: $124-30$.

23. Braun V, Clarke V. Using thematic analysis in psychology. Qual Res Psychol 2006;3:77-101.

24. O'Brien BC, Harris IB, Beckman TJ, Reed DA, Cook DA. Standards for reporting qualitative research: a synthesis of recommendations. Acad Med 2014;89:1245-51.

25. Tong A, Sainsbury P, Craig J. Consolidated criteria for reporting qualitative research (COREQ): a 32item checklist for interviews and focus groups. Int J Qual Health Care 2007;19:349-57.

26. Miller DP Jr, Latulipe C, Melius KA, Quandt SA, Arcury TA. Primary care providers' views of patient portals: interview study of perceived benefits and consequences. J Med Internet Res 2016;18:e8.

27. King J, Patel V, Jamoom EW, Furukawa MF. Clinical benefits of electronic health record use: national findings. Health Serv Res 2013;49(1 Pt 2):392-404.

28. Entzeridou E, Markopoulou E, Mollaki V. Public and physician's expectations and ethical concerns about electronic health record: Benefits outweigh risks except for information security. Int J Med Inform 2018;110:98-107.

29. Meigs SL, Solomon M. Electronic health record use a bitter pill for many physicians. Perspect Health Inf Manag 2016;13:1d. 
30. Beauchamp T, Childress J. Principles of biomedical ethics. 7th ed. Oxford, UK: Oxford University Press; 2012; 214-26.

31. Tierney WM, Alpert SA, Byrket A, et al. Provider responses to patients controlling access to their electronic health records: a prospective cohort study in primary care. J Gen Intern Med 2015;30:31-37.

32. Kim KK, Joseph JG, Ohno-Machado L. Comparison of consumers' views on electronic data sharing for healthcare and research. J Am Med Inform Assoc 2015;22:821-30.

33. Beauchamp T, Childress J. Principles of biomedical ethics. 7th ed. Oxford, UK: Oxford University Press; 2012;131-5.

34. Grünloh C, Cajander $\AA$, Myreteg G. "The record is our work tool!"-Physicians' framing of a patient portal in Sweden. J Med Internet Res 2016;18:e167.

35. Menachemi N, Collum TH. Benefits and drawbacks of electronic health record systems. Risk Manag Healthc Policy 2011;4:47-55.

36. Monteiro S, Norman G, Sherbino J. The 3 faces of clinical reasoning: Epistemological explorations of disparate error reduction strategies. J Eval Clin Pract 2018;24:666-73.
37. Asan O, Young HN, Chewning B, Montague E. How physician electronic health record screen sharing affects patient and doctor non-verbal communication in primary care. Patient Educ Couns 2014;98: 310-6.

38. Patel MR, Vichich J, Lang I. Developing an evidence base of best practices for integrating computerized systems into the exam room: a systematic review. J Am Med Inform Assoc 2017;24:e207-e215.

39. Bell SK, Mejilla R, Anselmo M, et al. When doctors share visit notes with patients: a study of patient and doctor perceptions of documentation errors, safety opportunities and the patient-doctor relationship. BMJ Qual Saf 2017;26:262-70.

40. Davidson SK, Schattner PL. Doctors' health-seeking behaviour: a questionnaire survey. Med J Aust 2003; 179:302-5.

41. Kay M, Mitchell G, Clavarino A, et al. Doctors as patients: a systematic review of doctors' health access and the barriers they experience. Br J Gen Pract 2008;58:501-8.

42. Kuhn CM, Flanagan EM. Self-care as a professional imperative: physician burnout, depression, and suicide. J Can Anesth 2017;64:158. 


\section{Appendix}

Interview Guide PCPs

Oral Informed Consent Script for PCPs:

We want to thank you for your willingness to participate in this study.

We are asking PCPs to help us by participating in interviews as part of a research study focusing on data sharing in and through the EHR. We would like to hear from you how you experience working with the EHR in your day-to-day practice, what strengths and weaknesses you see, and how you think about sharing information electronically with other care providers and patients.

Your participation will include being interviewed for approximately 45 minutes. The principal investigator, Tania Moerenhout (me), will conduct the interview. It will be audio recorded, but you will not be identified on this recording; interviews will be stored anonymously. If you prefer not to answer any of the questions, you may say so and the interviewer (I) will move on to the next question. Your insights from the interview will only be used for study purposes and to produce a report in a scientific journal which may be presented at scientific conferences. Your name or other identifiable information will not be mentioned. Your participation is completely voluntary: in case you want to withdraw from the study, you can do so at any time without any negative consequences. There are no particular risks involved in this study. Should you have any other questions or comments afterward, you can contact either the interviewer or the supervisor of this study. You will not be provided any incentive to take part in the research.

Do you agree?

\section{Background questions:}

Age; gender; years in practice; type of practice; hours of patient contact per week (consultation blocks); use of EHR program (which program, use of on-line appointment system); use of digital patient interactions (e-mail, Amwell, etc.).

\section{Topic 1: General Attitude Toward EHR, Use of EHR}

$>$ If you think about the last contact you had with a patient: Could you walk me through the different steps of the visit, and how you used the computer?

o Prompt: If you think about the start of the conversation, as of which point do you use the computer?
$>$ How do you integrate the use of the computer in the conversation with the patient and/or with other care providers?

$>$ How does the computer affect your interaction with the patient?

o Prompt: what efforts do you put in to reach (positive) or overcome (negative) this effect?

o Do you engage patients in this computer work?

o Do patients ask questions about their EHR?

\section{Topic 2: Impact on Quality of Care}

$>$ What influence would you say does the EHR have on the quality of care you provide?

$>$ What are the main benefits of the EHR use to you?

$>$ What are the main problems or pitfalls?

\section{Topic 3: Data Sharing; Shared Confidentiality (with Other Care Providers); Patient Access}

$>$ Thank you for your answers. I would like to talk a bit more about sharing information with other care providers and patients on-line. Let us start with other care providers. How do you experience the online sharing of patient information with other care providers?

$>$ When talking about digitally sharing patients' information with other care providers, 1 question that often comes up is how to handle sensitive information.

- First of all, what do you consider to be sensitive information in the EHR in this context?

- How do you handle this in the data sharing process?

- Prompt: specify sensitive information if necessary (reproductive/sexual bealth, substance abuse, mental bealth information, genetic information, domestic violence (NCVHS, see Caine et al, 2015))

$>$ Patients can also access their EHR. They can check certain parts of their record on-line, through the patient portal. Do you know what patients can or cannot see on the patient portal?

- How do you feel about patients accessing their records?

- Could you describe your experience with this function?

- According to you, what features or functions would an ideal patient access system have?

- Prompt: add, hide, remove information? 
$>$ Given these functions of data sharing with colleagues and with patients, does this influence the way you use the EHR?

\section{Topic 4: Multifunctionality of EHR}

$>$ We have just discussed 2 functions of the EHR, being data sharing with colleagues and patients_- of course it is used for more than that. I have created cards with 5 functions of the EHR, on which I would like to hear your input. According to you, how important is each function? Would you add any other functions, or leave out a certain one? ( 5 functions: storing of patient information/patient care, payment system (billing), quality-of-care control, generating research data, patient access/sharing of patient information).

\section{Topic 5: Digital Double/Digital Patient: Future}

I have one final question to round up this interview. Imagine you would treat a patient solely based on the EHR without knowing the patient beforehand/in real life: how would you respond to this? On what kind of conditions would you consider this?

Ok, thank you for your responses! Before we wrap up, would you like to add anything else? 